\title{
Revenue Management and Demand Fulfillment: Matching Applications, Models, and Software
}

\author{
Rainer Quante, Herbert Meyr and Moritz Fleischmann
}

\begin{tabular}{|l|l|}
\hline \multicolumn{2}{|l|}{ ERIM REPORT SERIES RESEARCH IN MANAGEMENT } \\
\hline ERIM Report Series reference number & ERS-2007-050-LIS \\
\hline Publication & August 2007 \\
\hline Number of pages & 29 \\
\hline Persistent paper URL & \\
\hline Email address corresponding author & mfleischmann@rsm.nl \\
\hline Address & Erasmus Research Institute of Management (ERIM) \\
& RSM Erasmus University / Erasmus School of Economics \\
& Erasmus Universiteit Rotterdam \\
& P.O.Box 1738 \\
& 3000 DR Rotterdam, The Netherlands \\
& Phone: $\quad+31104081182$ \\
& Fax: $\quad+31104089640$ \\
& Email: info@erim.eur.nl \\
& Internet: $\quad$ www.erim.eur.nl \\
\hline
\end{tabular}

Bibliographic data and classifications of all the ERIM reports are also available on the ERIM website: www.erim.eur.nl 


\section{ERASMUS RESEARCH INSTITUTE OF MANAGEMENT}

\section{REPORT SERIES \\ RESEARCH IN MANAGEMENT}

\begin{tabular}{|c|c|}
\hline \multicolumn{2}{|c|}{ ABSTRACT AND KEYWORDS } \\
\hline Abstract & $\begin{array}{l}\text { Recent years have seen great successes of revenue management, notably in the airline, hotel, } \\
\text { and car rental business. Currently, an increasing number of industries, including manufacturers } \\
\text { and retailers, are exploring ways to adopt similar concepts. Software companies are taking an } \\
\text { active role in promoting the broadening range of applications. Also technological advances, } \\
\text { including smart shelves and radio frequency identification (RFID), are removing many of the } \\
\text { barriers to extended revenue management. The rapid developments in Supply Chain Planning } \\
\text { and Revenue Management software solutions, scientific models, and industry applications have } \\
\text { created a complex picture, which appears not yet to be well understood. It is not evident which } \\
\text { scientific models fit which industry applications and which aspects are still missing. The relation } \\
\text { between available software solutions and applications as well as scientific models appears } \\
\text { equally unclear. The goal of this paper is to help overcome this confusion. To this end, we } \\
\text { structure and review three dimensions, namely applications, models, and software. } \\
\text { Subsequently, we relate these dimensions to each other and highlight commonalities and } \\
\text { discrepancies. This comparison also provides a basis for identifying future research needs. }\end{array}$ \\
\hline Free Keywords & $\begin{array}{l}\text { Revenue Management, Demand Fulfillment, Manufacturing, Software, } \\
\text { Advanced Planning Systems }\end{array}$ \\
\hline Availability & $\begin{array}{l}\text { The ERIM Report Series is distributed through the following platforms: } \\
\text { Academic Repository at Erasmus University (DEAR), DEAR ERIM Series Portal } \\
\text { Social Science Research Network (SSRN), SSRN ERIM Series Webpage } \\
\text { Research Papers in Economics (REPEC), REPEC ERIM Series Webpage }\end{array}$ \\
\hline Classifications & $\begin{array}{l}\text { The electronic versions of the papers in the ERIM report Series contain bibliographic metadata } \\
\text { by the following classification systems: } \\
\text { Library of Congress Classification, (LCC) } \underline{\text { LCC Webpage }} \\
\text { Journal of Economic Literature, (JEL), } \underline{\text { JEL Webpage }} \\
\text { ACM Computing Classification System CCS Webpage } \\
\text { Inspec Classification scheme (ICS), ICS Webpage }\end{array}$ \\
\hline
\end{tabular}




\title{
Revenue Management and Demand Fulfillment: Matching Applications, Models, and Software
}

\author{
Rainer Quante $^{1} \quad$ Herbert Meyr ${ }^{2} \quad$ Moritz Fleischmann ${ }^{3}$ \\ ${ }^{1}$ Institute for Production Management, Vienna University of Economics and Business Administration, \\ Nordbergstraße 15, 1090 Wien, Austria, rainer.quante@wu-wien.ac.at \\ ${ }^{2}$ Chair of Production and Supply Chain Management, Technical University of Darmstadt, Hochschulstr. 1, \\ 64289 Darmstadt, Germany, meyr@bwl.tu-darmstadt.de \\ ${ }^{3}$ RSM Erasmus University, P.O. Box 1738, 3000 DR Rotterdam, The Netherlands, MFleischmann@rsm.nl
}

August 2007

\begin{abstract}
Recent years have seen great successes of revenue management, notably in the airline, hotel, and car rental business. Currently, an increasing number of industries, including manufacturers and retailers, is exploring ways to adopt similar concepts. Software companies are taking an active role in promoting the broadening range of applications. Also technological advances, including smart shelves and radio frequency identification (RFID), are removing many of the barriers to extended revenue management. The rapid developments in Supply Chain Planning and Revenue Management software solutions, scientific models, and industry applications have created a complex picture, which appears not yet to be well understood. It is not evident which scientific models fit which industry applications and which aspects are still missing. The relation between available software solutions and applications as well as scientific models appears equally unclear. The goal of this paper is to help overcome this confusion. To this end, we structure and review three dimensions, namely applications, models, and software. Subsequently, we relate these dimensions to each other and highlight commonalities and discrepancies. This comparison also provides a basis for identifying future research needs.
\end{abstract}

Keywords: Revenue Management, Demand Fulfillment, Manufacturing, Software, Advanced Planning Systems

\section{Introduction}

Recent years have seen great successes of revenue management, notably in the airline, hotel, and car rental business. These successes essentially rely on identifying and exploiting differences in the customers' willingness to pay. Some approaches exploit these differences by offering multiple product variants, tailored to different customer segments, such as different fare classes in the airline industry. Other approaches stick to a single product variant but adjust its price dynamically over time, as practiced for example by many budget airlines but also by fashion retailers during end-of-season clearance sales. Currently, an increasing number of industries, including manufacturers and retailers, is exploring ways to adopt similar concepts. Software companies are taking an active role in promoting the transfer of revenue management concepts to a broader 
range of applications. Technological advances, such as smart retail shelves and RFID-tags for real-time inventory visibility further support this development by decreasing many potential barriers. Finally, increasing customer service and revenues through intelligent demand fulfillment provides a way for companies to respond to the ever increasing pressure of global competition.

The growing interest in revenue management applications is also reflected in intensified scientific research, as documented by a rapidly increasing number of publications (see e.g. Fleischmann et al., 2004). Supply Chain Planning and Advanced Planning software also is gradually incorporating ideas of revenue management. For example, they extend traditional availableto-promise and capable-to-promise-logic of Demand Fulfillment modules of Advanced Planning Systems (APS) to a profitable-to-promise logic (SAP, 2003). This development coincides with an ongoing consolidation in the APS market, from a multitude of small vendors, like Red Pepper or Numetrix, to a few big business application and business intelligence software companies, like Oracle or SAP. Nevertheless, many niche players remain successful, due to their "greater ability to manage the complexities of the supply chain, superior calculation power, greater agility, and improved integration capabilities achieved through open standards and service-oriented architectures" (ARC Advisory Group, 2006). Due to acquisitions, big software companies offer a wide range of Supply Chain Management modules (several dozens to more than a hundred), instead of just a few supply chain planning software packages. Consequently, these companies need to re-arrange and re-structure their supply chain management (SCM) software portfolios, as illustrated by the example of Oracle, that needs to position its own advanced planning solutions together with the supply chain planning, pricing, and demand management modules obtained through the acquisitions of Peoplesoft (including the former Red Pepper and Numetrix software), Retek, ProfitLogic, and Demantra (Oracle, 2007).

Given these rapid developments, it is not surprising that software companies, their customers, but also the scientific community are struggling to maintain a clear picture of the resulting situation: Which software modules serve which planning purpose in which business application? Which scientific models that have proven successful in a certain type of industry can be transferred and adapted to which other types of business with similar characteristics? The goal of this paper is to help overcome this confusion. To this end, we structure and review three dimensions, namely applications, models, and software. Subsequently, we relate these dimensions to each other and highlight commonalities and discrepancies. This comparison also provides a basis for identifying future research needs.

We do not pretend to cover every potential application, nor every modeling detail. Instead, we focus on a few prototypical cases ("types") on each dimensions. Moreover, within each dimension we build on existing reviews and classifications whenever possible.

The scope of our analysis includes the short- and mid-term demand fulfillment decisions in a supply chain. For this delineation we follow Fleischmann and Meyr (2004) who define the planning tasks of demand fulfillment relative to the position of the decoupling point, which divides the supply chain in forecast-driven and order-driven processes (Sharman, 1984, Hoekstra and Romme, 1992). Demand fulfillment, as understood in this article, comprises the decisions at and downstream of the decoupling point. These decisions are based on customer orders and primarily deal with managing the due dates of these orders.

We complement demand fulfillment with the concept of revenue management. According to Talluri and van Ryzin (2004), revenue management concerns demand management decisions aimed at increasing a firm's revenues. The authors distinguish quantity-based and price-based revenue management approaches. The first approach relies on exploiting customer heterogeneity. It segments customers in multiple classes and prioritizes them when allocating scarce capacity. The key idea is that giving priority to high-margin segments yields higher revenues than selling scarce capacity on a first-come-first-served basis. The second revenue-management approach uses 
pricing decisions as a lever for demand management. This includes adjusting prices dynamically over time, in response to non-stationary demand or a finite selling season, but also auctions as a price-discovery mechanism.

Traditionally, the demand fulfillment and APS perspective is common in manufacturing, whereas revenue management applications are mainly found in the service industries. In this paper we argue that the planning tasks of both concepts are actually very similar, and we systematically compare them. By highlighting analogies and distinctions, we aim to provide a basis for expanding the traditional domains of application of both concepts.

To summarize, our contribution is threefold. First, we unite the as of yet distinct concepts of demand fulfillment and revenue management and compare them to each other. Second, we link the three dimensions applications, models, and software and discuss alignments and discrepancies between them. We note that Elmaghraby and Keskinocak (2003) address similar aspects for dynamic pricing in a retail environment. Our paper differs from theirs by a broader scope in terms of planning tasks and applications. At the same time, we consider aggregated types of models in the literature, rather than reviewing individual modeling contributions. Third, we provide a supply chain framework for revenue management and demand fulfillment. We believe that many other applications beyond the examples illustrated in this paper are worth exploring. The presented framework provides a means for doing so in a systematic way.

The remainder of the paper is structured as follows. Section 2 introduces our framework, which we use for structuring the three dimensions applications, models, and software. Sections 3 through 5 analyze each of these dimensions separately. Section 6 then links the three dimensions and identifies alignments and discrepancies between them. Section 7 summarizes our main insights and discusses opportunities for future research.

\section{A Supply Chain Framework for Revenue Management and De- mand Fulfillment}

In this section, we present a framework, which we use in the remainder of the paper for a structured analysis of revenue management and demand fulfillment (RM\&DF) aspects in each of the three dimensions applications, models, and software. The framework is based on the elements of the supply chain depicted in Fig. 1. It is motivated by the aforementioned definition of demand fulfillment by Fleischmann and Meyr (2004). Recall that demand fulfillment concerns supply chain decisions downstream of the decoupling point (DP). At the same time, we can also represent revenue management decisions in this framework. We link pricing decisions to the item "final product" and capacity allocation decisions to the item "demand", respectively. We explain these elements in more detail below.

Our framework includes supply chain elements that are directly related to revenue management and demand fulfillment decisions. Specifically, we consider the following elements, from upstream to downstream: Replenishment represents either an external supplier or internal production. According to the definition of demand fulfillment, the replenishment policy at the DP of the receiving party is based on demand forecasts. This is a key point in our subsequent analysis. The decoupling point itself is the next element of our supply chain framework. It holds the inventory that is needed to hedge against forecast errors and replenishment uncertainty. The DP plays a pivotal role in our analysis since many RM\&DF decisions are dependent on the available inventory and on future replenishment orders. For a more detailed discussion of the DP concept and its impact in different production environments (including make-to-order (MTO), assemble-to-order (ATO) and make-to-stock (MTS)) we refer to Fleischmann and Meyr (2004). The supply chain may contain additional production processes downstream of the DP. For MTS 


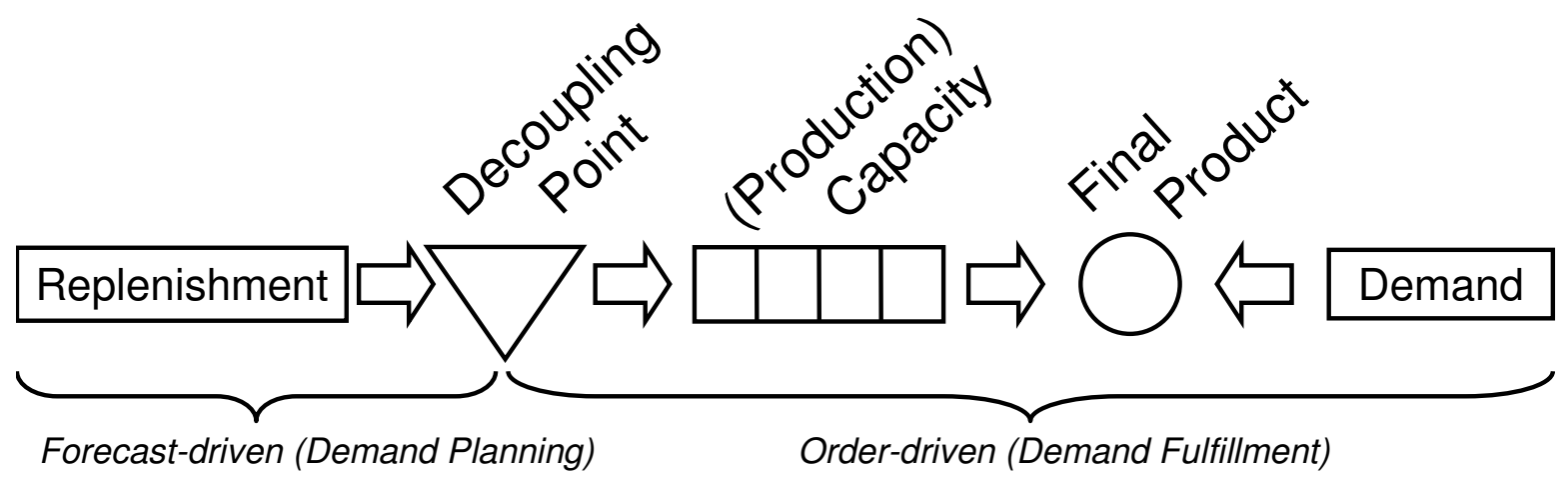

Figure 1: Supply chain framework

production this is not the case, since the DP holds the final product. In contrast, limited downstream capacity, possibly of multiple production stages, plays a critical role in a MTO supply chain. By definition, production downstream of the DP is order driven. Therefore, it has to be considered in the analysis to capture the effects of production lead times or order fulfillment. The most downstream elements of our framework concern the final product and corresponding customer demand.

RM\&DF concern decisions in the depicted supply chain and therefore depend on its specific characteristics. For example, the current inventory at the DP or the remaining production capacity may influence pricing decisions or promised due dates. By capturing these characteristics, the framework provides a systematic basis for identifying requirements for RM\&DF in different applications. Moreover, by structuring models and software tools in a similar way, we can compare the three dimensions to each other.

In order to characterize different types of supply chains we describe each element of the framework by a number of attributes, which are relevant to RM\&DF. Each supply chain then corresponds with a specific value for each attribute. For example, the product life cycle is an attribute of the final product, which can take the values short or long. We do not seek to describe every potential attribute of any given supply chain element but rather aim to focus on those attributes that are the most relevant to RM\&DF.

Using these attributes allows us to reduce the complexity of the intended comparison. Specifically, we group instances together in types that have the same or similar values in many attributes. In this way, we identify applications that have similar RM\&DF requirements. In addition, we can compare application, model, and software types to each other to see which tools are available for supporting RM\&DF decisions in a given context.

We proceed as follows. Sections 3 through 5 address applications, models, and software, respectively. In each case, we first introduce corresponding supply chain attributes and briefly discuss their potential values and their relevance to RM\&DF. Then we characterize a set of instances in terms of these attributes and cluster them into types. Section 6 then compares the types of the three dimensions.

\section{Industry applications}

In this section we analyze and compare RM\&DF decisions in different industries. As explained in the introduction, we do not seek completeness, but rather explore a set of examples that covers a broad range of different applications. To this end, we include examples from the service industries, retail, and manufacturing. Specifically, we look at the airline industry as a classical 


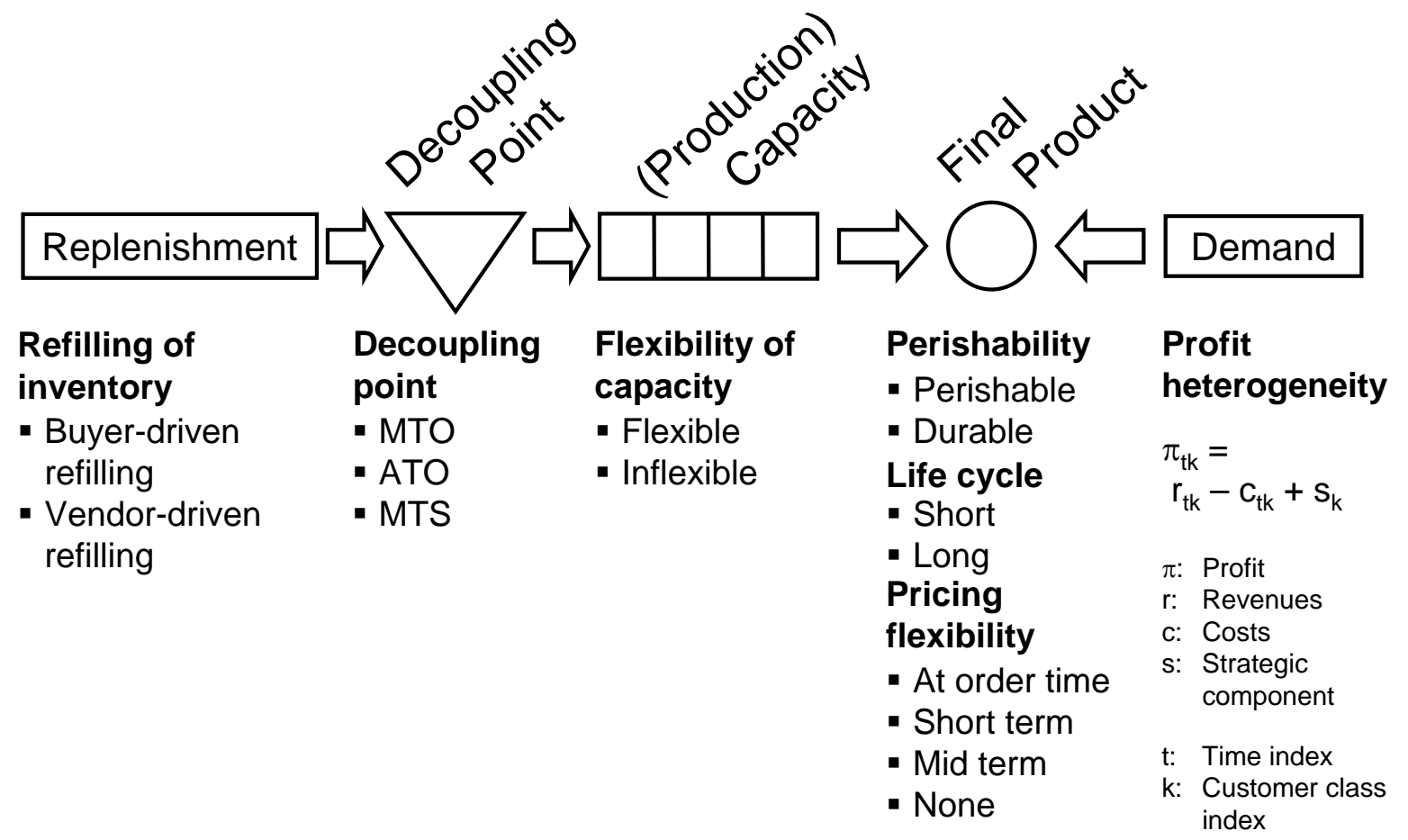

Figure 2: Supply chain framework: Application dimension

user of revenue management. Given their different demand management strategies, we make a distinction between premium and budget airlines. The retail sector is a driving force in many recent pricing strategies. We include the examples of fashion retail and consumer packaged goods in our analysis. Finally, we include three manufacturing examples that reflect different DPs, namely MTS, ATO, and MTO.

\subsection{Application-oriented supply chain attributes}

In order to analyze and compare RM\&DF decisions in these different environments we characterize them in terms of our supply chain framework. To this end, we consider the attributes depicted in Fig. 2, which we explain from upstream to downstream in what follows. Again, we do not claim completeness of our selection but rather focus on arguing why the selected attributes are relevant to RM\&DF. Table 1 at the end of this section summarizes the evaluation of the attributes for the aforementioned applications.

\subsubsection{Replenishment-related attributes}

At the upstream end of the framework, we distinguish different roles of the supply chain members with respect to the forecast-based replenishment of inventory located at the DP. We capture these differences in the attribute refilling of inventory. The famous "rationing game" considers a powerful supplier distributing scarce supply among his customers proportionally to their ordered quantities. This mechanism encourages customers to inflate orders in order to obtain the actually desired quantity. We denote situations in which suppliers have the power to decide on production and deliveries by the attribute value vendor-driven refilling. Rationing only occurs in the case of scarce supply capacity. If supply exceeds demand, orders will, in general, be fulfilled as requested. We describe this situation as buyer-driven refilling. 
If the supplier has the power to decide on deliveries this results in unreliable delivery times and limited replenishment capacity from the buyer's perspective. A more powerful buyer implies more reliable deliveries and a perception of unlimited supply capacity. In conclusion, the attribute affects the buyer's supply flexibility and thereby his fulfillment decisions.

To illustrate the application of this attribute consider the automotive industry, fashion retail and airlines. In automotive production, suppliers are usually in a weak position due to the vast competition on the market - hence refilling is buyer-driven. A similar situation occurs in the case of fashion retail, although this may differ between cheap and luxury fashion. For airlines, the concept of DP refilling does not really apply since seats are "sold" only temporarily (i.e. for a given flight) and no orders are placed to get new seats.

\subsubsection{Decoupling-point-related attributes}

As discussed in Section 2, the decoupling point represents a bundle of characteristics that separate forecast-driven from order-driven processes. Another common term is order penetration point. See Sharman (1984), Hoekstra and Romme (1992), Fleischmann and Meyr (2004), Meyr (2003) for a detailed analysis of the DP concept. We distinguish three attribute values.

In MTO production systems the DP lies upstream in the supply chain. Production is triggered by incoming customer orders. The inventory at the DP consists of raw materials, which are used in downstream production processes. The bottleneck in MTO usually concerns the production capacity downstream of the DP. MTO production is appropriate primarily for high-value and customer-specific products.

In $A T O$ systems, production downstream of the DP concerns the final product assembly. Inventory at the DP essentially consists of components that are usually delivered by external suppliers. Bottlenecks may concern either the DP inventory or the downstream assembly process.

MTS production is based on forecasts. Final products are produced on stock. This is a common strategy for standard products without customer-specific requirements.

The location of the DP has a strong impact on RM\&DF decisions by influencing customer service times, order fulfillment, and control of replenishment orders. For example, deciding on a (promised) delivery date is becoming more important as the DP moves upstream in the supply chain. At the same time, customer service times increase. Furthermore, the different production environments require different types of forecasts with different levels of aggregation.

The literature provides several real-life examples of RM\&DF in supply chains with different DPs. For example, Spengler et al. (2007) show an MTO application in the iron and steal industry. Harris and Pinder (1995) mention custom-made textile and custom equipment manufacturing as ATO examples. Meyr (2005) shows an application of MTS in the lighting industry. Given the scope of our paper, it is worth pointing out how the DP concept can be applied not only to manufacturing industries, but also to retail and service industries. In retail, inputs concern final products, while outputs concern sold products. The "production" process involves bundling and offering the right products at the right time, corresponding with MTS "production". In the case of a service business, "production" inputs include working time, material etc., and the output coincides with the transformation process. Since the "production" step is dependent on the customer's presence it can be characterized as MTO.

\subsubsection{Capacity-related attributes}

Similar to DP inventory replenishment, also the degree of flexibility of downstream capacity impacts a firm's fulfillment decisions by providing an alternative lever for matching supply and demand. Possibilities to adapt capacity levels to short-term demand fluctuations include, e.g., 
shutting down unnecessary machines or production lines in the case of excess capacity and hiring temporary workers or extending regular working hours in the case of shortages. General strategies for balancing capacities and demand can be found in, e.g., Chase and Aquilano (1995) or Bertrand (2003). These options may be further restricted by technical or regulatory requirements.

Evaluating this attribute for our application examples, we observe that airline capacity tends to be very inflexible in the short-term, due to long planning lead times for flight and crew schedules. In manufacturing, flexibility depends strongly on the technology used and on working-time agreements with labor unions. In the process industry, machines cannot easily be switched off due to the long and costly running-up phase. In contrast, computer manufacturing is highly flexible due to a high amount of manual tasks. In retail, capacity flexibility concerns changing opening hours and thus working times.

\subsubsection{Product-related attributes}

We observe several characteristics of the final product that impact RM\&DF. The first one is the degree of perishability, i.e. the maximum storage time. The values of this attribute range from perishable to durable. Perishability concerns the flexibility regarding the time horizon for selling the product. An inherent characteristic of perishable products is their low salvage value after expiration.

Product perishability has important consequences for RM\&DF. For perishable products, sales in the current period usually do not influence future sales. This is intuitive for necessity items that are frequently consumed. Moreover, since necessity items are consumed repeatedly, there is hardly a possibility for the customer to wait until the price decreases. Perishability also increases the importance of optimal replenishment. Since overstocking is expensive for perishable products, proper demand forecasts and corresponding optimal order quantities are crucial. In the case of durable goods, today's purchases may affect future sales. For example, a customer typically buys a computer only once within a few years. Therefore, price discounts early in the product life cycle may hurt future sales (Elmaghraby and Keskinocak, 2003).

Another relevant product-related attribute concerns the length of the product life cycle, i.e. the duration of the selling season. It can range from a few months, as in the case of fashion goods, to multiple years, as for basic food items.

The attribute has again a strong impact on RM\&DF. Short life cycles limit the availability of historical demand data and thereby complicate reliable forecasting. Moreover, due to the high frequency of new product releases, the customer will learn to anticipate the shape of the future price path. For example, video games usually have a short selling season and new ones are released frequently. Therefore, prices of video games are rapidly decreasing since they out-date quickly. Anticipating future prices, customers behave strategically and buy for their individual best price. In the case of long life cycles, anticipating on future prices is more difficult for the consumer, due to a lack of experience. We refer to Elmaghraby and Keskinocak (2003) for a more detailed discussion of this attribute.

A third product-related aspect worth considering is the degree of pricing flexibility, i.e. a company's possibilities to change prices. A customized product usually also has a customized price, as opposed to a standard product that sells for the same price during a longer time horizon. The attribute values range from changing at order time, as in the case of highly customized products, over short-term, up to mid-term price changes.

An on-line store may serve as an example of almost costless short-term price changes. Midterm price changes are found in industries where the physical or organizational requirements for frequent price changes are not given, as for example retail prices published in catalogs. Additionally, not only the frequency of price changes but also their potential magnitude characterizes 
the degree of pricing flexibility.

The impact on RM\&DF decisions is vast since, for example, price-based demand management relies crucially on pricing flexibility. If this flexibility is not given, quantity-based demand management by reserving products for specific customer segments is becoming more important.

\subsubsection{Demand-related attributes}

At the downstream end of our supply chain framework, we distinguish multiple ways in which profitability may differ between orders. We denote this attribute as profit heterogeneity. The formula in Fig. 2 displays three factors for differentiating in customer order profitability, namely revenues $r, \operatorname{costs} c$, and strategic importance $s$. Each of these factors may vary over time (denoted by the index $t$ ) and between customers (denoted by the index $k$ ).

For example, airlines often charge different prices according to the remaining booking time and other factors like remaining capacity, which implies different revenues $r_{t}$ at different points in time. Different fare classes, such as business and economy, represent an example of different revenues $r_{k}$ from different customer segments $k$ at the same point in time. In retail, different prices $r_{t}$ are charged at different points in time $t$ according to the remaining selling season however they typically apply to all customers.

Similarly, the costs of serving a customer order may also be a differentiator. Note that only those costs are relevant here, which can still be influenced when accepting the order. This includes, for example, transportation costs, taxes, and any variable costs of downstream production. Again, these costs can be invariant $(c)$, differ between customer classes $\left(c_{k}\right)$ and/or differ between different points in time $\left(c_{t k} / c_{t}\right)$.

Finally, customers may differ in their strategic importance, which may go beyond immediate costs and revenues. We capture this in our framework through the parameter $s$. For example, customers may be extremely important in terms of their ordered quantities or they may be loyal customers that should be treated better than occasional customers.

As discussed in the introduction, heterogeneity lies at the very heart of RM. Price-based approaches are driven by the time-dependence of the above profit elements. Quantity-based approaches seek to exploit customer segmentation. It is worth noting that segmentation may be attractive even in the case of constant unit revenues if the overall profit $\pi$ is heterogeneous due to varying costs (e.g. $\pi_{t k}=r-c_{t k}$ ) and/or different strategic importance (e.g. $\pi_{k}=r+s_{k}$ ). This contradicts the common claim that sunk costs of unused capacity are a major prerequisite for applying RM (e.g. Weatherford and Bodily, 1992). Meyr (2005) and Fischer (2001) describe applications of quantity-based approaches with strategically important customers.

\subsection{Application types}

Table 1 summarizes the various attribute values for the selected applications introduced at the beginning of this section. Missing attribute values indicate that an attribute is not applicable to the specific case. For example, the capacity flexibility attribute is not applicable to make-to-stock production since there is no production process downstream of the DP in this case. Capacity may be crucial upstream of the DP (as e.g. in consumer goods manufacturing where scarce production capacities often lead to push-based, "vendor-driven" refilling of finished goods inventories) but the production process can no longer be influenced upon order arrival and therefore does not make part of RM\&DF, as defined in Section 1.

Similarly, refilling of inventory is not applicable to the MTO cases. These examples illustrate that the different attributes in Table 1 are not mutually independent. We can therefore further simplify the characterization of the selected applications. Fig. 3 highlights that the appli- 


\begin{tabular}{|c|c|c|c|c|c|}
\hline $\begin{array}{l}\text { Application } \\
\text { Attribute }\end{array}$ & $\begin{array}{l}\text { Manufacturing: } \\
\text { Consumer } \\
\text { Goods }\end{array}$ & $\begin{array}{l}\text { Manufacturing: } \\
\text { Configurable } \\
\text { Computers }\end{array}$ & $\begin{array}{l}\text { Manufacturing: } \\
\text { Machines }\end{array}$ & $\begin{array}{l}\text { Service: } \\
\text { (Budget / Pre- } \\
\text { mium) Airlines }\end{array}$ & $\begin{array}{l}\text { Retail: (Fashion } \\
\text { Consumer Pack- } \\
\text { aged Goods) }\end{array}$ \\
\hline Refilling of inventory & Vendor-driven & $\begin{array}{l}\text { Partly vendor- } \\
\text { driven }\end{array}$ & & & Buyer-driven \\
\hline Decoupling point & MTS & ATO & MTO & MTO & MTS \\
\hline Flexibility of capacity & & Flexible & Flexible & Inflexible & \\
\hline Perishability & Durable & Durable & Durable & Perishable & Durable \\
\hline Life cycle & Long & Short & Long & Long & $\begin{array}{l}\text { Short / } \\
\text { Long }\end{array}$ \\
\hline Pricing flexibility & Mid-term & At order time & At order time & $\begin{array}{l}\text { Short-term / } \\
\text { Mid-term }\end{array}$ & $\begin{array}{l}\text { Short-term / } \\
\text { Mid-term }\end{array}$ \\
\hline Profit heterogeneity & $\pi_{\mathrm{tk}}=\mathrm{r}_{\mathrm{t}}-\mathrm{c}_{\mathrm{tk}}+\mathrm{s}_{\mathrm{k}}$ & $\pi_{\mathrm{tk}}=\mathrm{r}_{\mathrm{tk}}-\mathrm{c}_{\mathrm{k}}+\mathrm{s}_{\mathrm{k}}$ & $\pi_{\mathrm{tk}}=\mathrm{r}_{\mathrm{tk}}-\mathrm{c}_{\mathrm{k}}+\mathrm{s}_{\mathrm{k}}$ & $\begin{array}{l}\pi_{\mathrm{t}}=\mathrm{r}_{\mathrm{t}}-\mathrm{c} / \\
\pi_{\mathrm{k}}=\mathrm{r}_{\mathrm{k}}-\mathrm{c}\end{array}$ & $\pi_{\mathrm{t}}=\mathrm{r}_{\mathrm{t}}-\mathrm{c}$ \\
\hline
\end{tabular}

Table 1: Application examples

cations differ from each other with respect to the criteria supply flexibility and pricing flexibility. The first criterion combines the first three attributes of Table 1, whereas the second one corresponds directly with one of the original attributes. Note also that these criteria correspond with the main planning tasks among the list of attributes whereas the remaining attributes further describe the context.

We exploit the classification displayed in 3 for matching the application with available models and software in Section 6. In particular, we discuss the implications of the different degrees of flexibility on RM\&DF requirements. Before doing so however, we first address the model and the software dimensions separately.

\section{Models and methods}

\subsection{Model-oriented supply chain attributes}

This section addresses the model dimension of RM\&DF. Analogous with the previous section, we first discuss a number of model-oriented attributes of our underlying supply chain framework and then derive and review a set of distinct model types. Fig. 4 lists a number of attributes that we believe are relevant for characterizing RM\&DF models, as we discuss below. Again, we do not claim the list of attributes to be exhaustive.

We derive our model attributes from the basic elements of mathematical optimization models, namely decision variables, objective function, constraints, and input data. We do not address the objective function separately since the decision variables turn out to include sufficient information for our analysis. In addition, we jointly consider constraints and data as given model input. Fig. 4 displays potential decisions in straight bold characters and pure data attributes in bold italic.

A basic set of decision variables is derived from the product flow through the displayed supply chain. These concern the replenishment quantity at the DP $y_{t}$, the resulting inventory level $I_{t}$, and the number of customer orders accepted $x_{t k}$. As in the previous section, the index $t$ denotes the time dependence and $k$ indicates a distinction by customer class. These quantities are interrelated through the basic inventory balance equation $I_{t}=I_{t-1}+y_{t}-\sum_{k} x_{t k}$, stating that the inventory at the end of period $t$ is equal to the inventory at the end of the preceding period plus replenishment minus total accepted demand from all customer classes. Each of the 


\section{Supply Flexibility}

\begin{tabular}{|c|c|c|c|c|}
\hline & Capaci & -based (MTO) & Inventory-base & (MTS + ATO) \\
\hline & Inflexible & Flexible & Inflexible & Flexible \\
\hline $\begin{array}{l}\frac{0}{0} \\
\frac{0}{x} \\
\frac{0}{\frac{0}{E}}\end{array}$ & $\begin{array}{l}\text { Service: } \\
\text { Premium } \\
\text { Airlines }\end{array}$ & & $\begin{array}{l}\text { Manufacturing: } \\
\text { Consumer } \\
\text { Goods }\end{array}$ & $\begin{array}{c}\text { Retail: } \\
\text { Consumer } \\
\text { Pack. Goods }\end{array}$ \\
\hline $\begin{array}{ll}\frac{0}{0} & \frac{0}{0} \\
\frac{0}{2} & \frac{0}{1} \\
\frac{0}{4}\end{array}$ & $\begin{array}{l}\text { Service: } \\
\text { Budget } \\
\text { Airlines }\end{array}$ & $\begin{array}{l}\text { Manufacturing: } \\
\text { Machines }\end{array}$ & $\begin{array}{l}\text { Manufacturing: } \\
\text { Configurable } \\
\text { Computers } \\
\text { Retail: Fashion }\end{array}$ & \\
\hline
\end{tabular}

Figure 3: Different application types

factors in this equation may be modeled either as decision variables, as exogenous data, or it may not be considered at all (none).

We make the same distinction for the sales price $p_{t k}$ and also consider whether its domain is discrete or continuous. With respect to the production capacity downstream of the DP $a_{t}$ we distinguish between capacitated models (data), models with capacity as a decision (e.g. overtime), and uncapacitated models, which do not consider scarce capacity downstream of the DP (none).

In addition, we consider a few pure data attributes whose different values appear to be relevant to RM\&DF (see Figure 4). These include the replenishment lead time, which may be completely known (deterministic) or uncertain (stochastic), product perishability, and demand reliability. Many other attributes will be valuable for refining the analysis, such as salvage values, number of different products, backordering or lost sales, or the number of sales channels. However, in order not to overload our model we do not include all of these details in our analysis below.

\subsection{Model types}

Table 2 characterizes different streams of literature in terms of the attributes listed in Fig 4 . As for the different application types in Sect. 2, the different attributes in Table 2 turn out not to be independent. We therefore again condense the representation by concentrating on the most distinctive attributes. It turns out that pricing and order acceptance on the one hand and control over the replenishment quantity on the other hand suffice to reasonably identify most model types. Re-arranging the types results in the compressed view shown in Fig. 5.

Models in the first row of this figure take demand as entirely exogenous. They satisfy demand first-come-first-served (FCFS) at a given price. In particular, they do not involve any customer segmentation. The next two rows of Fig. 5 correspond with a more active demand management. Models in the second row still consider only a single customer class, but allow price changes which provide a lever for influencing demand. The last row shows models that explicitly recognize heterogeneous customers. In responding to a customer requests they have 


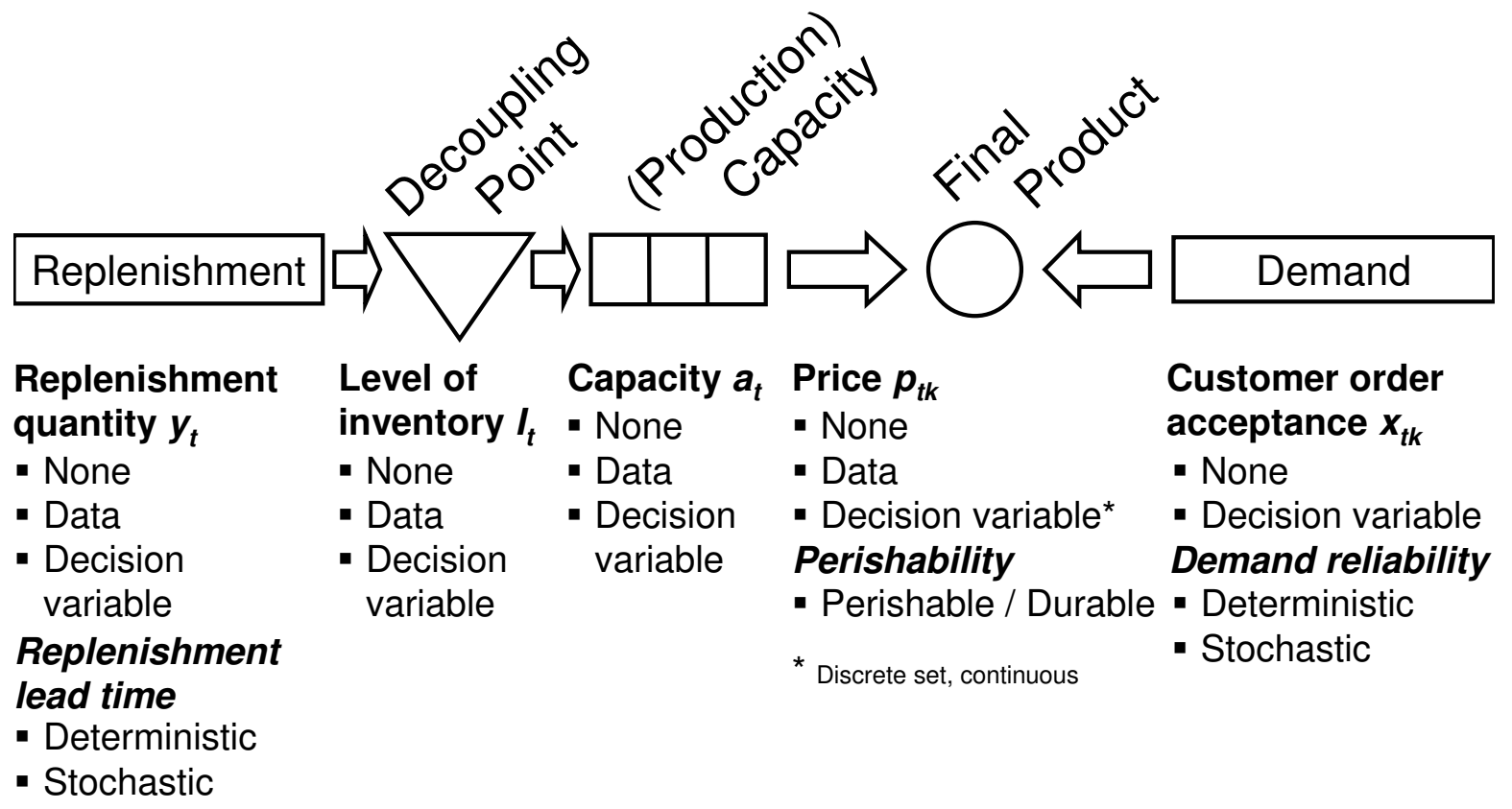

Figure 4: Supply chain framework: Model dimension

to make a trade-off between accepting a current, low-priority order now versus reserving the resources for high-priority orders expected in the future.

The demand side of Fig. 5 corresponds with the classification of RM-models of Talluri and van Ryzin (2004). We follow their terminology and label models as price-based or quantitybased. The columns reflect the way the different models consider inventory replenishment at the decoupling point. Note that both dimensions of the figure correspond with key decision variables regarding demand and supply. Also note that these dimensions are closely related to those of the application types discussed in the previous section. We analyze this analogy in detail in Section 6 .

In the remainder of this section, we briefly discuss each of the above model types. Given the scope of our analysis, we primarily build on available review papers in the literature, rather than to review individual models. Again, we see a more refined analysis as a valuable issue for future research.

\subsection{Review of model types}

\subsubsection{Single-class exogenous demand models}

We have not found any models fitting in the upper left cell of Fig. 5. This is not surprising since models with a given price and no consideration of replenishment or inventory, respectively, have nothing to decide on, neither on the demand nor on the replenishment side of the supply chain.

In the next cell to the right, the so-called order promising models consider price (i.e. demand), current inventory, and future replenishment quantities as given. This results in information about product availability and delivery times. For each incoming customer order the model decides real-time on the due date. The decision is made in a greedy fashion, purely based on availability. An introduction and overview of this so-called "real-time mode" or "single-orderprocessing" models is given in Ball et al. (2004), Chen et al. (2001), and Fleischmann and Meyr (2004). Additionally, a broad overview of due date management models with an emphasis on stochastic models is included in the work of Keskinocak and Tayur (2004). 


\begin{tabular}{|c|c|c|c|c|c|c|c|c|c|c|}
\hline $\begin{array}{l}\text { Model type } \\
\text { Attribute }\end{array}$ & $\begin{array}{c}\text { Order } \\
\text { Pro- } \\
\text { mising }\end{array}$ & \begin{tabular}{|c|} 
Stoch. \\
Inventory \\
Control
\end{tabular} & Pricing & $\begin{array}{c}\text { Markdown } \\
\text { Manage- } \\
\text { ment }\end{array}$ & $\begin{array}{c}\text { Trade } \\
\text { Promo- } \\
\text { tions }\end{array}$ & $\begin{array}{c}\text { Integrated } \\
\text { Pricing }\end{array}$ & aATP & $\begin{array}{l}\text { Tradi- } \\
\text { tional } \\
\text { RM }\end{array}$ & $\begin{array}{l}\text { Inventory } \\
\text { Rationing }\end{array}$ & Auctions \\
\hline Replenishment quantity & Data & Decision & None & None & Data & Decision & Data & None & Decision & None \\
\hline Replenishment lead time & Det/Stoch & Det. & & & Det. & Det. & Det. & & Det/Stoch & \\
\hline Level of inventory & Decision* & Decision* & None & Data & Data & Decision* & Decision* & None & Decision* & None \\
\hline (Production) Capacity & Data & None & None & None & None & None & Data & Data & None & None \\
\hline Price & Data: $p$ & Data: $p$ & Dec: $p_{t}$ & Dec: $p_{t}$ & Dec: $p_{t}$ & Dec: $p_{t}$ & Data: $p_{k}$ & Data: $p_{k}$ & Data: $p_{k}$ & Dec: $p_{t k}$ \\
\hline Perishability & Durable & Durable & Durable & Durable & Durable & Durable & Durable & Perish & Durable & Dur/Per \\
\hline Order acceptance & Dec: $x_{t}$ & Dec: $x_{t}$ & Dec: $x_{t}$ & Dec: $x_{t}$ & Dec: $x_{t}$ & Dec: $x_{t}$ & Dec: $x_{t k}$ & Dec: $x_{\mathrm{tk}}$ & Dec: $x_{t k}$ & Dec: $x_{t k}$ \\
\hline Demand reliability & Det/Stoch & Stoch & Stoch & Stoch & Stoch & Stoch & Det & Stoch & Stoch & Stoch \\
\hline
\end{tabular}

Table 2: Model examples

The upper right cell of Fig. 5 holds the vast class of stochastic inventory control (SIC) models, which focus on optimal inventory replenishment. Some of these models primarily address the structure of optimal replenishment policies, as for example the famous $(s, S)$-policy proven by Scarf (1960). Other models seek to determine optimal control parameters of such policies, such as the optimal ordering time, order quantity and inventory review intervals. Many SIC models build on the classical newsvendor model, which seeks to determine the optimal order quantity for a perishable product under stochastic demand. An overview of single-period newsvendor problems is given by Khouja (1999). Silver (1981) provides an overview and typology of many standard inventory problems, such as the ones mentioned above. General up-to-date overviews of inventory models can be found in the textbooks by Silver et al. (1998), Porteus (2002) and Tempelmeier (2006).

\subsubsection{Price-based models}

The model types in the middle row of Fig. 5 treat price as a decision, which influences the demand. Pure pricing models aim to determine an optimal selling price, without considering replenishments. For example, given a price-demand relation, the goal is to find the price which maximizes total revenues. Mild et al. (2006) review factors influencing demand and show how to find optimal prices.

Markdown models determine the right price path for inventory clearance for a given amount of inventory, which cannot be replenished during the planning horizon. Elmaghraby and Keskinocak (2003) classify several dynamic pricing models with and without replenishment decisions, the latter ones including markdown models.

Auctions, as discussed for example by Talluri and van Ryzin (2004, Sect. 6), take a fundamentally different approach to pricing. They provide a price-discovery mechanism and thereby an alternative to posting fixed prices. This approach is particularly valuable if little demand information is available. The aforementioned authors discuss the close connection between auctions and dynamic pricing.

Trade promotion models represent a type of pricing models that consider replenishments as an exogenous input and therefore fit in the second column of Fig. 5. Neslin (2002) provides an overview and discusses the reasons for promotions.

Research in integrated pricing (IP) models dates back to Whitin (1955) who extends 
Replenishment consideration

\begin{tabular}{|c|c|c|c|}
\hline & $\begin{array}{l}\text { None } \\
\text {-Replen. } y_{t}: \text { None }\end{array}$ & $\begin{array}{l}\text { Data } \\
\text { - Replen. } y_{t}: \text { Data }\end{array}$ & $\begin{array}{l}\text { Decision variable } \\
\text { - Replen. } y_{t} \text { : Decision } \\
\text { variable }\end{array}$ \\
\hline $\begin{array}{l}\text { Data } \\
\text { - Price p: Data } \\
\text { - Customer order acc. } x_{t} \text { : } \\
\text { Decision var. }\end{array}$ & - & $\begin{array}{c}\text { Order } \\
\text { Promising }\end{array}$ & $\begin{array}{l}\text { Stochastic } \\
\text { Inventory } \\
\text { Control }\end{array}$ \\
\hline $\begin{array}{l}\text { Price-based } \\
\text { - Price } p_{t} \text { : Decision var. } \\
\text { - Customer order acc. } x_{t} \text { : } \\
\text { Decision var. }\end{array}$ & $\begin{array}{l}\text { Markdown / } \\
\text { Pricing / } \\
\text { Auctions }\end{array}$ & $\begin{array}{c}\text { Trade } \\
\text { Promotions }\end{array}$ & $\begin{array}{c}\text { Integrated } \\
\text { Pricing }\end{array}$ \\
\hline $\begin{array}{l}\text { Quantity-based } \\
\text { - Price } p_{k} \text { : Data } \\
\text { - Customer order acc. } x_{k} \text { : } \\
\text { Decision var. }\end{array}$ & Traditional RM & aATP & $\begin{array}{l}\text { Inventory } \\
\text { Rationing }\end{array}$ \\
\hline
\end{tabular}

Figure 5: Different model types

the EOQ-formula as well as the classical newsvendor model with price decisions. This field has seen extensive research in the last decades, which is summarized, for example, by Petruzzi and Dada (1999). Recent research focuses on multiple period models, which are discussed in the well-known literature reviews of Chan et al. (2004), Elmaghraby and Keskinocak (2003) and Yano and Gilbert (2003). Few models exist for environments in which replenishment, prices and due dates are set simultaneously. Some models of this type and other models dealing with due date setting can be found, for example, in the previously mentioned review paper by Keskinocak and Tayur (2004).

From an application-oriented perspective it is worthwhile comparing IP and a successive application of pricing \& SIC models. While IP models recognize the interdependence between pricing and replenishment and therefore determine decisions simultaneously, they do so at the cost of a more simplified demand and supply representation. Pure pricing models may include sophisticated demand functions, including reference price effects, promotion effects, and competition (Mild et al., 2006). Similarly, SIC models consider factors such as multiple suppliers and quantity-discounts. IP models typically cannot deal with these factors due to tractability (Elmaghraby and Keskinocak, 2003, Sect. 4).

\subsubsection{Quantity-based models}

Models in the bottom row of Fig. 5 take prices as exogenous but manage demand by means of rationing strategies. In contrast with the models of the top row, the models distinguish multiple customer classes and prioritize them rather than fulfilling orders in a FCFS manner.

The type traditional revenue management (TRM) in the first cell of the third row refers to models that are common in airline applications. In these models, given units of a perishable product (e.g. seats on a flight on a specific day) are allocated to customers with different priorities or different willingness to pay. The basic question is whether to accept a given order or to reserve capacity in anticipation of more profitable future orders. McGill and van 
Ryzin (1999) and Pak and Piersma (2002) provide an overview and a short history of research in traditional revenue management with a focus on airline applications. Boyd and Bilegan (2003) discuss models focusing on e-commerce applications. The recent review by Chiang et al. (2007) includes an overview of RM practices in different industries.

Allocated available-to-promise models $(\boldsymbol{a A T P})$ are similar to the order promising type of the top row except for differentiating between multiple customer classes. Scarce resources (inventory on hand, planned stock at the DP or capacity downstream of the DP) are allocated to these classes according to customer profitability or other priority measures. Within each class, customer requests are usually handled FCFS, just as in traditional order promising. Guerrero and Kern (1988) introduce the general problem of accepting and refusing orders and discuss the requirements and implications of order promising mechanisms. For reviews of the mostly deterministic models of this type we refer to Kilger and Schneeweiss (2004b), Pibernik (2005) and Meyr (2005).

If customer requests do not have to be answered instantaneously several customer orders can be collected and jointly promised in a batch, thereby creating higher degrees of freedom for selecting the most important or profitable orders within a simultaneous optimization process. Overviews of these so-called "batch order promising models" can again be found in the work of Ball et al. (2004), Chen et al. (2001) or Fleischmann and Meyr (2004).

A review of integrated due-date management and job-scheduling models with deterministic orders is provided by Gordon et al. (2002). The article considers batch-models in which due dates are determined according to current capacity and the desired delivery date. Keskinocak and Tayur (2004) give a general overview of due-date setting models.

aATP and TRM models are similar in that they decide about demand fulfillment with respect to different customer classes. The most significant difference concerns the perishability of resources. TRM considers "perishable" products, e.g. empty seats on a specific flight, which are lost after the departure date, whereas the ATP quantities managed in aATP models are storable, in general. Another difference concerns the time horizon. TRM models typically consider a fixed day of capacity availability, e.g. the departure date of a flight. In contrast, aATP models consider multiple periods linked through the storability of excess inventory. Furthermore, aATP models usually assume deterministic demand whereas demand in TRM models is stochastic.

The last model type within our framework concerns inventory rationing (IR) models. Similar to the relationship between aATP and traditional order promising, IR models extend traditional SIC models by distinguishing and prioritizing multiple customer classes. For an early review we refer to Kleijn and Dekker (1998). As traditional SIC models, IR models may consider deterministic or stochastic replenishment lead times. A further distinction within this class of models concerns the number of demand classes considered, which may be general or limited to two classes.

For lack of recent reviews, we refer to a few individual articles that reflect two broad research streams within the type of IR models. Ha (1997) and De Véricourt et al. (2002) propose models with multiple demand classes and stochastic replenishment times, thus assuming limited production (= replenishment) capacities. In contrast, Melchiors et al. (2000) and Arslan et al. (2005) model deterministic replenishment lead times and unbounded replenishment quantities. All of these models take decisions on ordering and rationing levels, which are typically expressed in policies like $(s, S, R)$ where $s$ is the reorder point, $S$ the order-up-to level, and $R$ the protection level between customer classes.

IR and aATP models differ in terms of exogenous versus endogenous replenishment. Specifically, IR models consider replenishment decisions with stationary deterministic or stochastic lead times. In contrast, aATP typically considers capacitated, dynamic and deterministic arrivals of push-based production (= replenishment) quantities. To this end, aATP usually assumes deter- 
ministic and dynamic demand forecasts whereas IR models assume stochastic demand.

In addition to the model types captured in Fig. 5, a few recent research streams aim to combine several types by simultaneously considering multiple attributes. For example, Kocabıyıkoğlu and Popescu (2005) jointly analyze price and allocation decisions with two customer classes. Since most quantity-based models assume exogenous prices, this seems to be a promising direction for future research. Bitran and Caldentey (2003) formulate a general model of this problem and review the current state of research. Another approach is pursued in Ding et al. (2006) in which trade promotion models are combined with inventory rationing models. The authors denote the resulting new problem type by ADP, referring to the allocation of available stock, discounting and prioritization of customers.

\section{$5 \quad$ Software applications}

\subsection{Software types}

The software market for demand and supply chain solutions has changed in recent years. Whereas the focus was on the supply side for many years, the interest is now turning to end-to-end solutions including the demand side. Big supply chain solution providers like Oracle and SAP are investing large amounts into the acquisition of demand-related know-how. For example, in 2005 SAP took over Khimetrics, a leading vendor of markdown, price, and promotion-optimization solutions. As noted in Section 1, Oracle - after taking over one of its largest competitors in supply chain solutions, Peoplesoft, in 2005 - simultaneously invested in the demand solutions of Demantra (2006), ProfitLogic (2005) and Retek (2005), all of them leading vendors of retail revenue management software. Another big consolidation occurred in 2006 when JDA Softwarea provider of specialized retail solutions - took over Manugistics, a supply chain solution provider focusing on profit optimization in the consumer goods industry.

The scope of our current analysis is restricted to software supporting short-term decision making in RM\&DF. These solutions draw data from other software systems, such as Customer Relationship Management systems on the demand side (Buttle, 2004) and Enterprise Resource Planning systems (Stadtler and Kilger, 2004) on the supply side. Since these systems themselves do not focus on decision making we do not include them in our analysis.

As discussed in the previous section, scientific optimization models are fairly well described in the literature. One can easily identify data, decision variables, restrictions and solution strategies. Moreover, the solution quality is often analyzed in detailed numerical studies. This is different for commercial software solutions. Usually, available information is scarce and reveals little of the underlying technology. Software users can only assess the supported input data, available options, and the resulting output that is automatically calculated. The solution quality can hardly be evaluated objectively and is usually judged by user experience.

Our analysis of software modules reflects this limited availability of objective information. We build our characterization of software types and functionalities primarily on available software reviews and whitepapers. As a starting point we use essentially the same attributes and values as for the scientific models (see Fig.4). Model data and decisions roughly correspond with software input and output, respectively. Due to this correspondence, we omit a detailed discussion of attributes in this section.

Fig. 6 structures software types along the same axes as the model types in Section 4 . We choose names according to the functionality of commercial software modules on the market. The remainder of this section briefly reviews each of these software types. 
Replenishment consideration

\begin{tabular}{|c|c|c|c|}
\hline \multirow{3}{*}{ 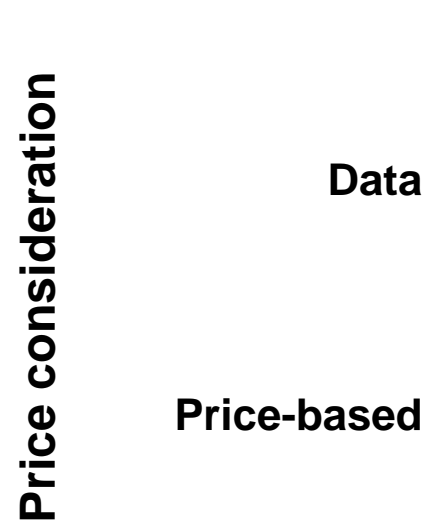 } & None & Data & Decision variable \\
\hline & - & $\begin{array}{c}\text { Traditional } \\
\text { Order Promising }\end{array}$ & $\begin{array}{l}\text { Purchasing \& } \\
\text { Materials } \\
\text { Requirements } \\
\text { Planning } \\
\end{array}$ \\
\hline & $\begin{array}{l}\text { Markdown- / } \\
\text { Pricing- / } \\
\text { Auction- } \\
\text { Management }\end{array}$ & $\begin{array}{l}\text { Promotion } \\
\text { Optimization }\end{array}$ & $\begin{array}{c}\text { Enterprise Profit } \\
\text { Optimization }\end{array}$ \\
\hline 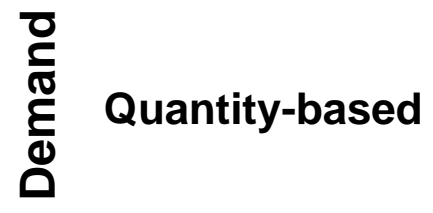 & $\begin{array}{c}\text { Revenue } \\
\text { Management }\end{array}$ & $\begin{array}{l}\text { Demand } \\
\text { Fulfillment \& } \\
\text { ATP }\end{array}$ & \begin{tabular}{|l} 
Master \\
Planning
\end{tabular} \\
\hline
\end{tabular}

Figure 6: Different software types

\subsection{Review of software types}

\subsubsection{Single-class exogenous demand solutions}

The mid upper cell of Fig. 6 denoted by traditional order promising contains traditional software modules for short-term order promising under known inventory availability. When a customer order arrives, the software simply determines whether the order can be satisfied out of available inventory. If not, the order is backlogged according to a standard lead time without considering future capacity or additional incoming supply. It is easy to see that this approach can lead to an order peak after the standard lead time and thus to severe capacity problems in the future. Kilger and Schneeweiss (2004b) illustrate this situation in a simple example.

Refilling of inventory is usually left to purchasing $\mathcal{G}$ materials requirements planning modules, which are part of enterprise resource planning (ERP) systems. Essentially, these systems can deal with refilling of non-bottleneck material and components from a single vendor. An overview of these classical systems can be found, for example, in the textbook of Vollmann et al. (2005). Since these classical systems provide sufficient solution quality only for very simple settings, specialized inventory modules consider extensions such as capacitated replenishment, stochastic demand, and multiple suppliers (Stadtler, 2004). Such modules usually are part of larger advanced planning and supply chain planning software suites. Additionally, there are specialized vendors of supply-chain wide inventory optimization tools, such as Optiant (Optiant, 2007) with its inventory suite Powerchain and Smartops (Smartops, 2007).

\subsubsection{Price-based solutions}

Markdown management systems are mainly used in retail, for example for end-of-season stock clearance. An example of markdown management systems is B_Line, described by Mantrala and Rao (2001) under the name MARK. The system takes possible prices and corresponding 
demand probability distributions for each period as inputs and can find both markdown and markup price paths. The output consists of a specific price in each period. Furthermore, MARK is capable of finding a suitable amount of initial inventory by iterating through a discrete set of possible inventory levels. Elmaghraby and Keskinocak (2003, Sect. 3.2) describe the capability of markdown solutions.

Software systems of the type pricing management are relatively new. This is due to the vast requirements of computing power and availability of past sales data. The rise of data warehouses and cheap computing power has recently been allowing the use of automated pricing systems for many applications. Pricing management systems are based on complex pricedemand functions for which suitable parameters have to be estimated, which usually requires a vast amount of past sales data. For example, to estimate price elasticity, the sales data has to include a certain degree of diversity, corresponding with at least a few past price changes. Capacity or inventory restrictions are usually not considered in these types of software (see for example Mild et al., 2006).

The quick expansion of e-commerce applications has boosted the use of auction systems. The vast number of different systems merits a review in its own right and exceeds the scope of our analysis. We refer to Kambil and van Heck (2002) for a systematic introduction to this field. Vakali et al. (2001) discuss the characteristics of internet-based auction system and present a short survey of popular applications.

Similar to the previously described markdown systems, promotion optimization is also used in retail environments, as described by Elmaghraby and Keskinocak (2003, Sect. 3.2). Very detailed information about the capability of such systems can be found on-line, for example from the vendors mentioned at the beginning of this section.

The term enterprise profit optimization (EPO) was coined by the software company Manugistics, claiming to be the first vendor offering an integrated pricing and supply solution (Manugistics, 2002). Furthermore, the Manugistics software is meant to be able to allocate scarce resources to the most profitable customers, thus simultaneously applying ideas of quantity-based RM\&DF. Demand and supply planning is realized in many solutions, but not in an integrated way and not including price decisions. Most APS forecast demand for different price levels and then successively analyze - within the context of mid-term planning - several what-if scenarios and their effects on the total supply chain.

\subsubsection{Quantity-based solutions}

APS software modules that support mid-term, aggregated supply and demand decisions are known as master planning modules (Meyr et al., 2004b). They receive deterministic demand forecasts and prices as inputs from the demand planning module of APS (Wagner, 2004) and then determine the best combinations of sales, production and replenishment quantities and the corresponding inventories under given capacity constraints. Quantities can be allocated to different customer classes. In terms of our supply chain framework in Fig. 1, master planning modules deal with forecast-driven demand planning (i.e. push-based, vendor-driven refilling of the DP) and therefore fall outside the scope of our definition of RM\&DF. However, we feel that they deserve mention since their resulting allocations serve as the primary input for the short-term, capacity-checked order promising, that is executed by Demand Fulfillment and ATP modules of APS. A detailed list of options considered in master planning modules can be found in the work of Rohde and Wagner (2004).

By taking capacity and inventory replenishments into account, demand fulfillment $\mathbb{G}$ $\boldsymbol{A T P}$ modules of APS extend the aforementioned traditional order promising. They determine due dates for incoming customer orders, which promise to be more reliable than simple standard 
lead times. In addition, if ATP quantities are allocated to customer priority classes - which is usually implemented in an aggregated way - order promising differentiates with respect to customer importance, based on customer profitability or strategic impact.

To find a reliable due date for a customer order, the software searches for demand fulfillment alternatives according to pre-defined "search dimensions". These include the time dimension, i.e. checking for ATP back- or forwards in time, the product dimension, i.e. substitute products, the location dimension, and the customer dimension, i.e. checking for availability in other priority classes (Kilger and Schneeweiss, 2004b). Usually, the software systems do not take the profitability of different fulfillment alternatives into account during this search. However, recent systems not only consider available-to-promise quantities (available inventory) or capableto-promise quantities (available capacity), but also follow a profitable-to-promise (PTP) logic that enables them to compare customer orders and fulfillment alternatives according to their priority. Usually, simple rules are defined as search strategies for the different dimensions (Meyr et al., 2004a, Sect. 18.2.1).

Revenue management software is widely used by airlines, hotel chains, and car rental agencies. RM software systems basically take the given capacity and offered tariffs as input and decide on acceptance or rejection of customer orders. One of the main differences with demand fulfillment \& ATP is that RM software focuses on revenues rather than costs. Furthermore, RM systems usually forecast demand in much more detail than demand-fulfillment modules, e.g. for each flight, on each day, and for each customer class. These forecasts require a large amount of historical sales data in order to be reliable. Modern revenue management systems can handle many additional industry-specific issues, such as overbooking and connecting flights in the airline context (Talluri and van Ryzin, 2004, Sect. 10.1.3, 11.2).

\section{Matching applications, models, and software}

In this section we match the three previously discussed dimensions applications, models, and software with each other in order to identify alignments and misalignments. In particular, our goal is to identify the most appropriate models and software types for RM\&DF decisions in the different types of applications introduced in Sect. 3, namely service, retail, and manufacturing and to highlight remaining research needs.

We build our argumentation around the structure of Figures 3, 5, and 6. Specifically, we compare the supply flexibility observed in a given application with the way that replenishment decisions are supported by different model and software types. Similarly, we tie the observed demand flexibility to the supported demand management. In this way, we identify for each application the most appropriate cell(s) in Figures 5 and 6. Subsequently, we discuss the match/mismatch with models and software within that cell in more detail by including the additional attributes highlighted in the preceding sections. This allows us to recognize empty spots and future research needs.

Fig. 7 summarizes the match between the different types of applications and the main model and software attributes. In the remainder of this section we explain this match by application type.

\subsection{Service industries}

Remember that service industries can be characterized as MTO since the "production" step requires the presence of the customer. Hence, replenishment decisions do not play a role and one primarily needs to consider available capacity downstream of the decoupling point (currently available seats in an airplane). This suggests that the first column of Figures 5 and 6 is the most 
Replenishment

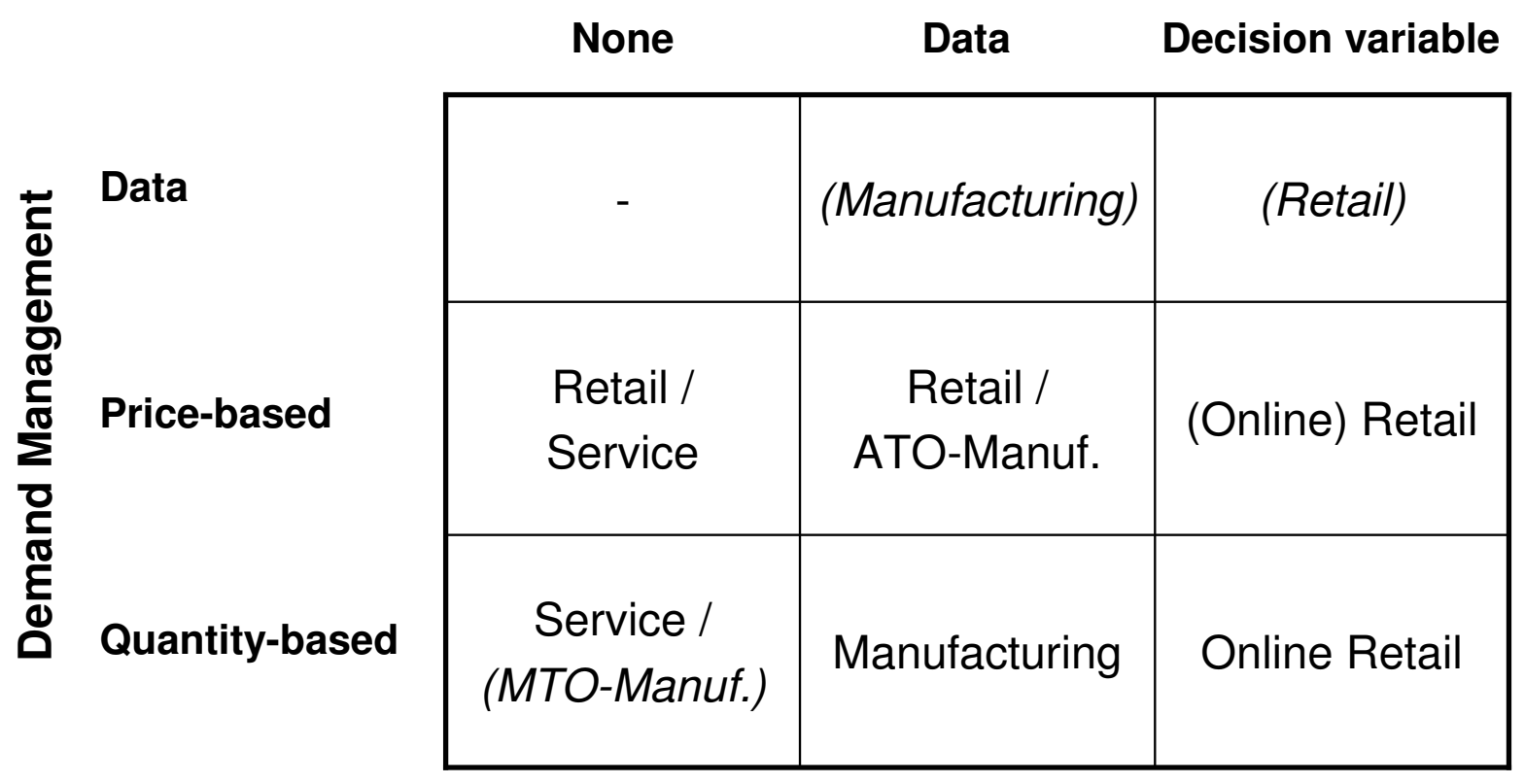

Figure 7: RM\&DF in different applications

relevant for service industries.

Moreover, since capacity is inflexible and cannot be substituted nor stored, the means for matching supply to demand are limited, which makes demand management the main lever in the short term. Models and methods in the top row of our figure hardly support this step and therefore appear insufficient for these applications. A more intelligent way of demand management is required, which recognizes the customers' willingness to pay. This can be achieved either through price-based (second row) or quantity-based (third row) RM\&DF, which renders models and software of the type markup/-down, pricing, and (traditional) revenue management the most intuitive candidates (see Figures 5, 6 and 7).

Which of these types are best suited essentially depends on the pricing flexibility and possibility of customer segmentation. This corresponds with the two examples of service applications sketched in Section 3, namely budget and premium airlines. Because of their on-line pricing flexibility, budget airlines can use markup models and software to determine the (increasing) mid-term price path of a certain flight, as well as short-term temporary discounts. Premium airlines benefit from tailoring fairs to specific customer segments, which leads to the quantity-based approaches of traditional revenue management.

Of course, these matches are hardly surprising since they confirm well-known common practice. However, the examples show that our approach is able to identify these matches correctly. This supports the application of the same approach to less obvious examples as in the cases in the following subsections.

\subsection{Retail}

Inventory replenishment in retail environments is primarily buyer-driven (see Table 1) and thus endogenous. This suggests the third column of Figures 5 and 6 as the most appropriate in this context. However, there are exceptions. For example, when replenishment decisions are made on the mid-term and cannot be revised on the short-term (e.g. in the fashion industry due to the long lead times and short life cycles) replenishment has to be taken for granted at the time of 
order fulfillment or it may be non-existent altogether. Similarly, replenishments may be of little concern in the case of ample capacity and short lead times. Thus, the first two columns may also be relevant to retail.

Under the general assumption of buyer-driven inventory replenishment and the MTS decoupling point, supply and production can be considered as relatively unproblematic in retail (see Sect. 3). On the other hand, retail is close to the final consumer and therefore has a traditional focus on price setting, even if prices can only be changed on the mid-term. Therefore, the second row of our scheme is of primary interest. Because of the relatively simple supply and production requirements, all of the price setting models in this row appear relevant under certain circumstances. This includes pricing models (e.g. if inventory cannot or need not be considered), markdown models (for short life cycles), trade promotion models (for long life cycles with given replenishment contracts), and integrated pricing models (with simultaneous replenishment decisions).

Similarly, the corresponding software types, namely pricing, markdown management, promotion optimization, and EPO software, can be applicable, with the appropriate choice depending on the detailed application attributes in Table 1. All of these models and software can be applied on the mid-term, or on the short-term if pricing flexibility is high enough.

Opportunities for customer segmentation (third row) are more limited in a retail environment, in general. It is hard to collect sufficient data for identifying natural consumer segments or to define and fence off "artificial" consumer segments analogous to the service industries. Fencing usually requires additional services (e.g. business customers receiving bonus miles, preferred transfer etc.) which may not be obvious in retail and essentially requires a shift from a purely product-oriented retailer to a more general service provider. Other examples of segmentation in retail include the selling of a product as part of a bundled package, or the use of multiple distribution channels (Agatz et al., 2007) Inventory rationing models can then be applied for refilling and allocating stock to different channels.

Online retailers face particularly promising opportunities for gathering data for customer segmentation as well as for changing prices almost instantaneously. Therefore, they can integrate price- and quantity-based RM with flexible replenishment strategies. Models (and software) for this type of application are rare and offer promising research opportunities (see also Sect. 4).

\subsection{Manufacturing}

Our third main application type concerns the manufacturing industries. Unlike in the preceding application types, production processes are the most important, and usually most costly, process steps in this case. The decoupling point as the interface between forecast-driven demand planning and customer-oriented demand fulfillment (see Fig. 1 and Sect. 3) describes whether a certain production process is operated under demand (un)certainty, what type of stocks (raw material, components, final products) have to be held, where the main bottlenecks (stocks, production capacity) can be expected, and how long customer service times are. Because of these significant differences we consider MTS, ATO, and MTO manufacturing applications separately.

\subsubsection{Make-to-stock.}

In MTS environments, all production processes are executed forecast-based. Due to upstream capacity limitations, production planning decides on short-term replenishment of DP inventories in a push-based, "vendor-driven" manner. Thus, models including replenishment decisions (third column of Fig. 5) can only support the mid-term, forecast-based demand planning, but not the short-term demand fulfillment. In order to make use of the (uncertain) information on future 
DP inventory replenishments, as implied by the production plans, demand fulfillment models of the second column appear the most appropriate.

Because of the MTS market conditions and contracting practice, pricing decisions typically have to be taken on a mid-term basis (see Table 1). For example, the Demand Planning module of an APS forecasts several price-demand scenarios, including e.g. different alternatives for price discounts or promotions. These scenarios are passed to the master planning module, which checks each of them with respect to supply chain constraints, selects the most profitable one, and generates directives for the (forecast-based) short-term production planning. Thus, short-term pricing flexibility is rather limited, which rules out the models and software on the second row of Fig. 5 for demand fulfillment in MTS-manufacturing. Price-based approaches appear mainly applicable on the mid-term planning level, e.g. to determine demand forecasts in conjunction with optimal prices.

This leaves us with order promising and aATP models as the most applicable models for RM\&DF in MTS manufacturing. Both of them consider the current level of DP inventory. Order promising in a MTS environment searches through the ATP quantities in a FCFS manner to be able to fulfill a customer order. Newer approaches process several customer orders in a batch and allocate ATP to the most profitable customer orders. Due date setting is not relevant in this environment. aATP models overcome the disadvantage of batch order promising, namely not providing a real-time order promise and forcing the customer to wait. However, they are dependent on forecast-based information on DP inventories, that is provided by the master and production plans, and on the possibility of customer segmentation. The ATP search rules that are used to consume the allocated ATP quantities of the different customer classes follow similar ideas as traditional RM methods. However, since products in MTS manufacturing are durable and can be stored (see Table 1), they also have to be able to "search over time", i.e. to take future inventory replenishments into account.

\subsubsection{Assemble-to-order.}

In ATO production, the most important supply chain elements are the inventory kept at the DP (components to be assembled) and the scarce assembly capacity downstream of it. Since customer order service times are longer than in MTS environments, order promising becomes more difficult and more important. In addition, new customer-oriented planning tasks arise, such as supply and demand matching and the short-term production planning of the assembly process(see Fleischmann and Meyr, 2004).

To determine the suitable columns in Figures 5 and 6 , one has to consider whether or not replenishments can be controlled in the short term (third column). For the aforementioned example of configurable computer manufacturing, long replenishment lead times essentially rule out this option. If availability of the computer components, e.g. high-end CPUs, is limited and they cannot be replenished as required (i.e. vendor-driven), an integrated demand fulfillment and replenishment is impossible, which rules out the third column. On the other hand, DP inventory is as important in ATO as in MTS and thus information about future replenishments should not be neglected. Otherwise promised due dates will not be reliable. Therefore, again, models of the first column (especially traditional RM methods) are not appropriate or at least have to be adapted to these needs.

In general, the capacity downstream of the DP involves some degree of flexibility. Therefore, demand management is less important for matching supply and demand than in entirely inflexible environments (see service applications above). However, ATO usually concerns customized products, and therefore yields opportunities for customer segmentation and exploiting differences in willingness to pay. Therefore, the focus of ATO RM\&DF should lie on selling the 
available resources to the different customer segments in the most profitable way. aATP models and software (third row of Figures 5 and 6 ) outperform the simpler FCFS order promising (first row) in that respect.

For real-time order promising, the advantages of aATP over a FCFS logic are similar to the ones in the MTS case, except that multi-stage bills-of-material have to be taken into account. Batch order (re-)promising models, however, are more important in the ATO case because they can also be applied for supply-demand-matching (which is part of the short-term production planning), i.e. to select the most important customer orders to release next to the shop floor for assembly. Standard APS software can be used for this purpose (see Kilger and Schneeweiss, 2004a), but usually does not provide as sophisticated methods as the corresponding optimization models (Ball et al., 2004).

For customized products, pricing can also be part of order promising because prices often are only communicated upon customer request, due to the high number of potential product configurations. However, traditional trade promotion models and software as listed in the central cell of Figures 5 and 6 are not appropriate for this planning task. On the other hand, traditional pricing or EPO models / software usually do not take into account future inventory availability at the DP, as determined by the mid-term production planning. Therefore, we see room for future research on price-based RM\&DF with given replenishments.

Even though their business model is recently being criticized, Dell has shown that direct selling can build a bridge between traditional manufacturing and traditional retail and that pricing flexibility - at least for non-standard components such as additional memory - can be increased through direct access to customers. In this case, both pricing flexibility and customer segmentation can be exploited simultaneously. Therefore, as noted for the case of on-line retailing in the previous subsection, integrated price- and quantity-based approaches offer further research opportunities, also for ATO manufacturing.

\subsubsection{Make-to-order.}

In MTO production all, usually multi-stage and very complex, production processes are executed to order and production capacity is critical. In contrast, DP inventory only consists of basic materials that can be easily replenished. Therefore, replenishment decisions are of lesser importance and we can concentrate on models and software of the first and second column of Figures 5 and 6 . Although short-term productions planning is now also customer-oriented and thus part of demand fulfillment we mainly focus on the order promising aspects of MTO in what follows. The key task is to quote reliable due dates and to decide which orders to accept in order to maximize profit.

Pricing flexibility in an MTO setting is high. However, automatic price-based approaches do not seem applicable because prices for the usually complex and expensive MTO-products have to be negotiated, in general. Standard pricing software (second row) cannot really be used for determining minimum acceptable prices either since sufficient past sales data is hardly available for the highly customized products in MTO. A more appropriate way of finding minimum acceptable prices may be by using the production planning software to assess marginal costs, e.g. by simulating production plans with and without the given order. Due to the complexity of the production system this can often only be done in an aggregate, approximate manner.

Similar to ATO, the high customization of MTO-products offers opportunities for segmentation strategies, provided that the customer base is sufficiently heterogeneous to identify and separate different segments. Customers of MTO-products are naturally segmented by the differences in production costs between different orders. Therefore, fencing may not be needed.

We further narrow the choice of appropriate cells of Figures 5 and 6 by noting that the 
underlying models and software have to consider available production capacity. This leaves us with the model types of order promising, aATP, and traditional revenue management. Traditional RM assumes fixed production costs, non-flexible capacity and perishability. These assumptions apply to only a few, exceptional MTO industries (e.g. perishable products in some chemical industries). In most other cases traditional RM has at least to be modified to be able to support due-date setting in MTO production.

Traditional order promising models for MTO focus on due date setting under limited production capacities. They either check CTP quantities in a FCFS manner (Dickersbach, 2004, Kilger and Schneeweiss, 2004b), estimate due dates by means of stochastic queuing theory (Keskinocak and Tayur, 2004), or simulate the short-term production planning deterministically, as discussed above. Whereas the first and the last types of models are usually implemented in standard APS, the second type is only found in specialized software.

Differences in the profitability of customer orders are not exploited by traditional order promising models. Some APS allow a profitability assessment of different fulfillment alternatives by evaluating their revenues and costs during the rule-based (ATP and) CTP check. The aATP logic can be extended similarly for additional CTP checks. This again allows prioritizing different customer segments, thereby transferring RM ideas to MTO manufacturing. However, since CTP quantities represent production capacities only in a very aggregate manner, the resulting due dates and thus also the estimated profits are not very reliable for complex production systems. In this case a more detailed simulation of short-term, customer-oriented production planning, as described above, appears necessary. This however often yields prohibitively long computation times, which also imply long reaction times to customer requests.

Of course, short-term production planning models and software can also be applied to batch promising of multiple customer orders, which offers additional degrees of freedom. However, the approach suffers from the same inherent problems as in the single-order case. We conclude that the biggest challenge in MTO order promising is not so much the availability of models and software but how to implement them in practice so as to strike a good balance between solution quality/reliability and short response times.

\section{Conclusion}

In this paper, we have analyzed and structured revenue management (RM) and demand fulfillment (DF) decisions. We have presented a framework that covers the underlying supply chain processes and allows for a systematic comparison of different business environments.

The conceptual integration of revenue management and demand fulfillment is a major contribution of this paper. Both concepts have emerged in different industries. Demand fulfillment is a standard component of advanced planning systems that are mainly applied in manufacturing industries. Revenue management, on the other hand, is tightly linked to service industries, notably to airline ticket sales. These different backgrounds and associated terminology and connotations complicate a systematic comparison and thus a mutual exchange of ideas between both concepts. In this paper, we argue that revenue management and demand fulfillment actually concern essentially the same supply chain processes.

The main conceptual distinction regards a different degree of demand management. Traditional DF essentially treats demand as exogenous. It assumes given prices and treats customer orders in a first-come-first-served manner. For each incoming customer order it searches for the fastest fulfillment possibility and promises a corresponding due date to the customer. In contrast,

RM seeks to more actively manage demand. It considers short-term price adjustments and prioritizes different customer segments, thereby exploiting differences in the customers' willingness 
to pay.

The framework introduced in Fig. 1 in Sect. 2 allows for a uniform treatment of RM and DF decisions. In this paper, we have applied it to characterize and compare a few exemplary application environments. The selected examples are far from comprehensive. Yet they serve to demonstrate the applicability of our framework, which we hope will be useful for analyzing many other examples. Moreover, the framework also supports a classification of RM and DF models and software systems. We have identified two key distinctive factors, namely the aforementioned demand management and the replenishment strategy at the supply chain decoupling point. Similar to the former, the latter can be endogenous or exogenous. We have used both of these factors (see Figures 5-7) to structure reviews of optimization models and software systems, which are relevant for RM\&DF, and to compare them to the requirements of selected applications in the service, retail, and manufacturing industries in Sect. 6 .

This led to the following main insights (cp. also Fig. 7):

- Replenishment is not an issue in service industries. Scarce capacities (e.g. of seats in an airplane, hotel rooms, etc.), which cannot be stored and thus also not be replenished, are in the center of attention. Therefore, fewer means are available for balancing supply (=capacities) and demand than in other industries, which motivated the early use of RM techniques. On the other hand, adapting these traditional RM techniques for manufacturing or retail applications requires the integration of replenishment and storability.

- Retail is closest to the end consumer. Production and limited production capacities do not play a noteworthy role, but replenishment is important and can take on different shapes. Various types of price-based demand management are applicable here. Possibilities for differentiated stock allocation are still limited. Exceptions include multi-channel retailing, where some channels may have priority over others, or on-line retailing, where a lot of information about customer behavior is available and the customers do not see the physical inventories.

- Manufacturing industries are very heterogeneous. Inventory holding, replenishment and limited production capacities can occur separately or in any combination, and the means for balancing supply, capacity, and demand are manifold. Thus, an active demand management in the sense defined above was not as important in the past as in service industries and is still in its infancy today. However, it arouses more and more interest. The decoupling point concept helps structure the variety of manufacturing applications. The major potential for a more active demand management seems to lie in differentiated capacity allocation, i.e. quantity-based RM\&DF. A short-term pricing potential is mainly given for ATO-manufacturing, due to the high degree of customization in combination with a pressure for short customer order lead times.

Unlike in service environments, order promising in manufacturing industries is a multi-period problem, i.e. production earlier or deliveries later than the customer's requested date are possible. Therefore, traditional RM techniques typically cannot be applied as is, except possibly in a few MTO manufacturing industries. Otherwise, they have to be adapted to deal with the holding and (future) replenishment of decoupling point inventory (MTS, ATO), costs (MTS, ATO, MTO) and throughput-time estimates for downstream processes (ATO, MTO). The allocation and ATP consumption rules currently used in APS serve this purpose, but are very basic. We see a need for future research here. Incorporating further ideas of traditional (quantity-based) RM might lead to more sophisticated methods and software.

Additionally, we have identified further promising research opportunities: In on-line retail the integration of price- and quantity-based demand management ideas with flexible replen- 
ishment strategies seems to offer interesting potentials. The same is true for direct sellers in ATO-manufacturing who additionally have to take care of the product assembly.

For due-date re-promising and demand-supply-matching, which are further planning tasks of ATO manufacturing, batch optimization models appear helpful and have already been proposed in the scientific literature. However, to develop optimization methods that are scalable to practical needs and can find their way into commercial planning software, further research seems necessary.

Last but not least, short-term production planning and scheduling modules of APS already offer the basic functionality to estimate the due dates and costs of a certain customer request in complex MTO environments. However, for most practical applications the effort in terms of modeling complexity and computation time is still too high. Thus we see an interesting trade-off between detailed but complex cost and throughput time projection models as a basis for demand management and simpler but possibly less accurate projections. But even when this problem can eventually be handled the question will remain how to use these projections in price negotiations with the customer and whether another customer is about to call who is willing to pay an even higher price.

Acknowledgments. The authors are grateful to the Vienna Science and Technology Fund (WWTF) for funding this research.

\section{References}

Agatz N, Fleischmann M, van Nunen J (2007) E-fulfillment and multi-channel distribution - A review. European Journal of Operational Research (in press)

ARC Advisory Group (2006) Supply chain planning worldwide outlook. URL http://www . arcweb.com/StudyPDFs/Study_scp.pdf

Arslan H, Graves SC, Roemer T (2005) A single-product inventory model for multiple demand classes. Working paper 4542-05, Massachusetts Institute of Technology (MIT), Sloan School of Management

Ball MO, Chen CY, Zhao ZY (2004) Available-to-promise. In: Simchi-Levi D, Wu SD, Shen ZJ (eds.) Handbook of quantitative supply chain analysis - Modeling in the e-business era. Kluwer Academic Publishers, pp 447-483

Bertrand JWM (2003) Supply chain design: Flexibility considerations. In: de Kok A, Graves S (eds.) Supply chain management: Design, coordination and operation. Elsevier, vol. 11, pp $133-198$

Bitran G, Caldentey R (2003) An overview of pricing models for revenue management. Manufacturing \& Service Operations Management 5(3):203-229

Boyd EA, Bilegan IC (2003) Revenue management and e-commerce. Management Science 49(10):1363-1386

Buttle F (2004) Customer relationship management, 1st edn. Butterworth Heinemann, Oxford

Chan LMA, Shen ZJM, Simchi-Levi D, Swann JL (2004) Coordination of pricing and inventory decisions: A survey and classification. In: Simchi-Levi D, Wu SD, Shen ZJ (eds.) Handbook of quantitative supply chain analysis - Modeling in the e-business era. Kluwer Academic Publishers, pp 335-392 
Chase RB, Aquilano NJ (eds.) (1995) Production and operations management: Manufacturing and services, 7 th edn. Irwin, Chicago

Chen CY, Zhao ZY, Ball MO (2001) Quantity and due date quoting available to promise. Information Systems Frontiers 3(4):477-488

Chiang WC, Chen JCH, Xu X (2007) An overview of research on revenue management: current issues and future research. International Journal of Revenue Management 1(1):97-128

De Véricourt F, Karaesmen F, Dallery Y (2002) Optimal stock allocation for a capacitated supply system. Management Science 48(11):1486-1501

Dickersbach JT (ed.) (2004) Supply chain management with APO. Springer, Berlin Heidelberg New York

Ding Q, Kouvelis P, Milner JM (2006) Dynamic pricing through discounts for optimizing multiclass fulfillment. Operations Research 54(1):169-183

Elmaghraby W, Keskinocak P (2003) Dynamic pricing in the presence of inventory considerations: Research overview, current practices, and future directions. Management Science 49(10):1287-1309

Fischer ME (2001) "Available-to-Promise": Aufgaben und Verfahren im Rahmen des Supply Chain Management. Theorie und Forschung Band 704, Wirtschaftswissenschaften Band 63. Roderer, Regensburg

Fleischmann B, Meyr H (2004) Customer orientation in advanced planning systems. In: Dyckhoff H, Lackes R, Reese J (eds.) Supply chain management and reverse logistics. Springer, pp 297321

Fleischmann M, Hall JM, Pyke DF (2004) Smart pricing. MIT Sloan Management Review $45(2): 9-13$

Gordon V, Proth JM, Chu C (2002) A survey of the state-of-the-art of common due date assignment and scheduling research. European Journal of Operational Research 139:1-25

Guerrero HH, Kern GM (1988) How to more effectively accept and refuse orders. Production and Inventory Management Journal 29(4):59-63

Ha AY (1997) Inventory rationing in a make-to-stock production system with several demand classes and lost sales. Management Science 43(8):1093-1103

Harris FH, Pinder JP (1995) A revenue management approach to demand management and order booking in assemble-to-order manufacturing. Journal of Operations Management 13(4):299309

Hoekstra S, Romme JE (1992) Integral logistic structures: Developing customer-oriented goods flow. McGraw-Hill, London

Kambil A, van Heck E (2002) Making markets: How firms can design and profit from online auctions and exchanges. Harvard Business School Press, Boston

Keskinocak P, Tayur S (2004) Due-date management policies. In: Simchi-Levi D, Wu SD, Shen ZJ (eds.) Handbook of quantitative supply chain analysis - Modeling in the e-business era. Kluwer Academic Publishers, pp 485-547 
Khouja M (1999) The single-period (news-vendor) problem: Literature review and suggestions for future research. Omega 27:537-553

Kilger C, Schneeweiss L (2004a) Computer assembly. In: Stadtler H, Kilger C (eds.) Supply chain management and advanced planning, 3rd edn. Springer, Berlin Heidelberg New York, pp 389-406

Kilger C, Schneeweiss L (2004b) Demand fulfilment and ATP. In: Stadtler H, Kilger C (eds.) Supply chain management and advanced planning, 3rd edn. Springer, Berlin Heidelberg New York, pp 179-196

Kleijn MJ, Dekker R (1998) An overview of inventory systems with several demand classes. Econometric institute report 9838/a, RSM Erasmus University

Kocabıyıkoğlu A, Popescu I (2005) Joint pricing and revenue management with general stochastic demand. Working paper, INSEAD

Mantrala MK, Rao S (2001) A decision-support system that helps retailers decide order quantities and markdowns for fashion goods. Interfaces 31(3):146-165

Manugistics (2002) Enterprise profit optimization. URL http://www.manugistics.com/ documents/epo_whitepaper.pdf

McGill JI, van Ryzin G (1999) Revenue management: Research overview and prospects. Transportation Science 33(2):233-256

Melchiors P, Dekker R, Kleijn M (2000) Inventory rationing in an (s, Q) inventory model with lost sales and two demand classes. Journal of the Operational Research Society 51(1):111-122

Meyr H (2003) Die Bedeutung von Entkopplungspunkten für die operative Planung von Supply Chains. Zeitschrift für Betriebswirtschaft 9:1-22

Meyr H (2005) Customer segmentation, allocation planning and order promising in make-to-stock production. Working paper, Vienna University of Economics and Business Administration

Meyr H, Rohde J, Wagner M, Wetterauer U (2004a) Architecture of selected APS. In: Stadtler H, Kilger C (eds.) Supply chain management and advanced planning, 3rd edn. Springer, Berlin Heidelberg New York, pp 341-354

Meyr H, Wagner M, Rohde J (2004b) Structure of Advanced Planning Systems. In: Stadtler H, Kilger C (eds.) Supply chain management and advanced planning, 3rd edn. Springer, Berlin Heidelberg New York, pp 109-116

Mild A, Natter M, Reutterer T, Taudes A, Wöckl J (2006) Retail revenue management. In: Schnedlitz P, Buber R, Reutterer T, Schuh A, Teller C (eds.) Innovationen in Marketing und Handel. Linde, Wien, pp 124-143

Neslin SA (2002) Sales promotion. In: Weitz BA, Wensley R (eds.) Handbook of marketing. Sage Publications, London, pp 310-338

Optiant (2007) URL http://www.optiant.com

Oracle (2007) Strategic acquisitions. URL http://www.oracle.com/corporate/acquisition. html 
Pak K, Piersma N (2002) Airline revenue management: An overview of OR techniques 1982-2001. Econometric Institute Report 256, Erasmus University Rotterdam

Petruzzi NC, Dada M (1999) Pricing and the newsvendor problem: A review with extensions. Operations Research 47(2):183-194

Pibernik R (2005) Advanced available-to-promise: Classification, selected methods and requirements for operations and inventory management. International Journal of Production Economics 93-94:239-252

Porteus EL (2002) Foundations of stochastic inventory theory. Stanford University Press

Rohde J, Wagner M (2004) Master planning. In: Stadtler H, Kilger C (eds.) Supply chain management and advanced planning, 3rd edn. Springer, Berlin Heidelberg New York, pp 159178

SAP (2003) Profitable-to-promise: The next step in the evolution of order promising. URL http://www.sap.com/solutions/business-suite/scm/pdf/BWP_profit-to-promise.pdf

Scarf H (1960) The optimality of (s,S) policies for the dynamic inventory problem. In: Arrow KJ, Karlin S, Suppes P (eds.) Mathematical methods in the social sciences. Stanford University Press, Stanford, California, pp 196-202

Sharman G (1984) The rediscovery of logistics. Harvard Business Review 62(5):71-79

Silver EA (1981) Operations research in inventory management: A review and critique. Operations Research 29(4):628-645

Silver EA, Pyke DF, Peterson R (eds.) (1998) Inventory management and production planning and scheduling, 3rd edn. Wiley

Smartops (2007) URL http://www.smartops.com

Spengler T, Rehkopf S, Volling T (2007) Revenue management in make-to-order manufacturing - an application to the iron and steel industry. OR Spectrum 29(1):157-171

Stadtler H (2004) Purchasing and material requirements planning. In: Stadtler H, Kilger C (eds.) Supply chain management and advanced planning, 3rd edn. Springer, Berlin Heidelberg New York, pp 215-227

Stadtler H, Kilger C (eds.) (2004) Supply chain management and advanced planning, 3rd edn. Springer, Berlin, Heidelberg, New York

Talluri KT, van Ryzin GJ (2004) The theory and practice of revenue management. Kluwer Academic Publishers

Tempelmeier H (2006) Inventory management in supply networks. problems, models, solutions. Norderstedt: Books on Demand

Vakali A, Angelis L, Pournara D (2001) Internet based auctions: a survey on models and applications. ACM SIGecom Exchanges 2(1):6-15

Vollmann TE, Berry WL, Whybark DC (2005) Manufacturing planning and control for supply chain management, 5th edn. Mcgraw-Hill 
Wagner M (2004) Demand planning. In: Stadtler H, Kilger C (eds.) Supply chain management and advanced planning, 3rd edn. Springer, Berlin Heidelberg New York, pp 139-158

Weatherford LR, Bodily SE (1992) A taxonomy and research overview of perishable-asset revenue management: Yield management, overbooking, and pricing. Operations Research 40(5):831844

Whitin TM (1955) Inventory control and price theory. Management Science 2(1):61-68

Yano CA, Gilbert SM (2003) Coordinated pricing and production/procurement decisions: A review. In: Chakravarty AK, Eliashberg J (eds.) Managing business interfaces: Marketing, engineering and manufacturing perspectives. Kluwer Academic Publishers, Norwell, Massachusetts, International Series in Quantitative Marketing, pp 65-103 


\section{Publications in the Report Series Research ${ }^{*}$ in Management}

\section{ERIM Research Program: "Business Processes, Logistics and Information Systems"}

2007

India: a Case of Fragile Wireless Service and Technology Adoption?

L-F Pau and J. Motiwalla

ERS-2007-011-LIS

http://hdl.handle.net/1765/9043

Some Comments on the Question Whether Co-occurrence Data Should Be Normalized

Ludo Waltman and Nees Jan van Eck

ERS-2007-017-LIS

http://hdl.handle.net/1765/9401

Extended Producer Responsibility in the Aviation Sector

Marisa P. de Brito, Erwin A. van der Laan and Brijan D. Irion

ERS-2007-025-LIS

http://hdl.handle.net/1765/10068

Logistics Information and Knowledge Management Issues in Humanitarian Aid Organizations

Erwin A. van der Laan, Marisa P. de Brito and S. Vermaesen

ERS-2007-026-LIS

http://hdl.handle.net/1765/10071

Bibliometric Mapping of the Computational Intelligence Field

Nees Jan van Eck and Ludo Waltman

ERS-2007-027-LIS

http://hdl.handle.net/1765/10073

Approximating the Randomized Hitting Time Distribution of a Non-stationary Gamma Process

J.B.G. Frenk and R.P. Nicolai

ERS-2007-031-LIS

http://hdl.handle.net/1765/10149

Application of a General Risk Management Model to Portfolio Optimization Problems with Elliptical Distributed Returns for Risk Neutral and Risk Averse Decision Makers

Bahar Kaynar, S. Ilker Birbil and J.B.G. Frenk

ERS-2007-032-LIS

http://hdl.handle.net/1765/10151

Optimal Zone Boundaries for Two-class-based Compact 3D AS/RS

Yugang Yu and M.B.M. de Koster

ERS-2007-034-LIS

http://hdl.handle.net/1765/10180

Portfolios of Exchange Relationships: An Empirical Investigation of an Online Marketplace for IT Services

Uladzimir Radkevitch, Eric van Heck and Otto Koppius

ERS-2007-035-LIS

http://hdl.handle.net/1765/10072

From Closed-Loop to Sustainable Supply Chains: The WEEE case

J. Quariguasi Frota Neto, G. Walther, J.Bloemhof, J.A.E.E van Nunen and T.Spengler

ERS-2007-036-LIS

http://hdl.handle.net/1765/10176 
A Methodology for Assessing Eco-Efficiency in Logistics Networks

J. Quariguasi Frota Neto, G. Walther, J.Bloemhof, J.A.E.E van Nunen and T.Spengler

ERS-2007-037-LIS

http://hdl.handle.net/1765/10177

Strategic and Operational Management of Supplier Involvement in New Product Development: a Contingency Perspective Ferrie E.A. van Echtelt, Finn Wynstra and Arjan J. van Weele

ERS-2007-040-LIS

How Will Online Affiliate Marketing Networks Impact Search Engine Rankings?

David Janssen and Eric van Heck

ERS-2007-042-LIS

Modelling and Optimizing Imperfect Maintenance of Coatings on Steel Structures

R.P. Nicolai, J.B.G. Frenk and R. Dekker

ERS-2007-043-LIS

Human Knowledge Resources and Interorganizational Systems

Mohammed Ibrahim, Pieter Ribbers and Bert Bettonvil

ERS-2007-046-LIS

Is Management Interdisciplinary? The evolution of management as an interdisciplinary field of science and education in the Netherlands

Peter van Baalen and Luchien Karsten

ERS-2007-047-LIS

Revenue Management and Demand Ful Ilment: Matching Applications, Models, and Software

Rainer Quante, Herbert Meyr and Moritz Fleischmann

ERS-2007-050-LIS

* A complete overview of the ERIM Report Series Research in Management: https://ep.eur.nl/handle/1765/1

ERIM Research Programs:

LIS Business Processes, Logistics and Information Systems

ORG Organizing for Performance

MKT Marketing

F\&A Finance and Accounting

STR Strategy and Entrepreneurship 